\title{
Energetics of Multidecadal Atlantic Ocean Variability
}

\author{
HENK A. DIJKSTRA \\ Institute for Marine and Atmospheric Research Utrecht, Department of Physics and Astronomy, \\ Utrecht University, Utrecht, Netherlands \\ JUAN A. SAENZ* \\ Research School of Earth Sciences, The Australian National University, Canberra, Australian Capital Territory, Australia \\ ANDREW MCC. HOGG \\ Research School of Earth Sciences and ARC Centre of Excellence for Climate System Science, \\ The Australian National University, Canberra, Australian Capital Territory, Australia
}

(Manuscript received 15 November 2012, in final form 16 April 2014)

\begin{abstract}
Oscillatory behavior of the Atlantic meridional overturning circulation (MOC) is thought to underlie Atlantic multidecadal climate variability. While the energy sources and sinks driving the mean MOC have received intense scrutiny over the last decade, the governing energetics of the modes of variability of the MOC have not been addressed to the same degree. This paper examines the energy conversion processes associated with this variability in an idealized North Atlantic Ocean model. In this model, the multidecadal variability arises through an instability associated with a so-called thermal Rossby mode, which involves westward propagation of temperature anomalies. Applying the available potential energy (APE) framework from stratified turbulence to the idealized ocean model simulations, the authors study the multidecadal variability from an energetics viewpoint. The analysis explains how the propagation of the temperature anomalies leads to changes in APE, which are subsequently converted into the kinetic energy changes associated with variations in the MOC. Thus, changes in the rate of generation of APE by surface buoyancy forcing provide the kinetic energy to sustain the multidecadal mode of variability.
\end{abstract}

\section{Introduction}

There is now ample observational evidence for the existence of coherent spatiotemporal decadal-to-multidecadal variability in the climate system. One prominent example is the Atlantic multidecadal oscillation (AMO), which is characterized by multidecadal variations in North Atlantic sea surface temperature and sea level height. From available sea surface temperature observations the

\footnotetext{
* Current affiliation: Climate, Ocean and Sea Ice Modeling, Theoretical Division, Los Alamos National Laboratory, Los Alamos, New Mexico.

Corresponding author address: Henk A. Dijkstra, Institute for Marine and Atmospheric Research Utrecht, Dept. of Physics and Astronomy, Utrecht University, Princetonplein 5, 3584 CC Utrecht, Netherlands.

E-mail: h.a.dijkstra@uu.nl
}

time scale of variability can be roughly divided into a longer period of 50-70 years (Schlesinger and Ramankutty 1994; Kushnir 1994; Enfield et al. 2001) and a shorter period of 20-30 years (Frankcombe et al. 2008; Frankcombe and Dijkstra 2009).

A recent analysis of several time series, each 1000 years long, of oxygen isotope data from Greenland ice cores has shown that both time scales are present in the proxy data but that the $20-30-y r$ variability is more pronounced than the 50-70-yr variability (Chylek et al. 2011). Multidecadal variability has also been observed in the Arctic (Venegas and Mysak 2000), in the temperature of Atlantic water entering the Arctic Ocean (Polyakov et al. 2004) as well as in sea ice extent (and thickness) in Arctic marginal seas (Polyakov et al. 2003).

In general circulation models (GCMs) used in the Intergovernmental Panel on Climate Change (IPCC) Fourth Assessment Report (AR4), different dominant time scales are found. In the Geophysical Fluid 
Dynamics Laboratory Coupled Model version 2.1 (GFDL CM2.1) a 20-30-yr time scale (Zhang 2008) is dominant, the Hadley Centre Coupled Model version 3 (HadCM3) displays both 25-yr (Dong and Sutton 2005) and 100-yr variability (Vellinga and Wu 2004), and the coupled ECHAM5-Max Planck Institute Ocean Model version 1 (ECHAM5-OM1) shows predominantly a 7080 -yr variability (Jungclaus et al. 2006). By looking at control runs of various coupled climate models, several different mechanisms have been proposed to describe the physics of the multidecadal temperature changes. The mechanisms variously explain the variability as an ocean response to low-frequency atmospheric variability (Delworth et al. 1993; Delworth and Greatbatch 2000; Eden and Jung 2001), a delayed advective oscillation of the Atlantic Ocean circulation (Lee and Wang 2010), a coupled ocean-atmosphere mode (Timmermann et al. 1998) in which the North Pacific may play a role (Dima and Lohmann 2007), a connection between the tropical and northern Atlantic (Vellinga and Wu 2004; Knight et al. 2005), or a connection between the North Atlantic and Arctic Oceans (Jungclaus et al. 2005).

An alternative approach has been to study Atlantic multidecadal climate variability using idealized models that represent only a limited number of physical processes. In single-hemispheric ocean basin models, the multidecadal variability then arises as a large-scale instability of the meridional overturning circulation (MOC). The anomaly pattern corresponding to this instability is an internal (normal) ocean mode, a so-called thermal Rossby mode (Huck et al. 1999; Te Raa and Dijkstra 2002). The internal mode can be excited by atmospheric noise with spatiotemporal characteristics of the North Atlantic Oscillation (Frankcombe et al. 2009). In fact, a thermal Rossby mode can be observed in the laboratory (Vincze et al. 2012) as the only ingredients needed are an overturning flow, rotation, and surface heat flux noise.

The thermal Rossby mode mechanism has recently also been found in a state-of-the-art ocean general circulation model (Sevellec and Fedorov 2013). The pattern and time scale of the thermal Rossby mode are consistent with observations of westward propagating temperature anomalies in the North Atlantic (Frankcombe et al. 2008) and sea level variations along the European and North American coastlines (Frankcombe and Dijkstra 2009), both of which occur on the shorter 20-30-yr time scale. Such 20-30-yr variability is consistent with the dominant variability found in ice core records (Chylek et al. 2011). In Frankcombe and Dijkstra (2011) the 50-70-yr variability was attributed to processes in the Arctic and involves salinity anomalies that propagate to the Atlantic, where they effect the MOC. This is also consistent with the results from ice core records (Chylek et al. 2012), where the $50-70-y r$ variability is larger in northern Greenland (which is more affected by processes in the Arctic) than in southern Greenland (which is more affected by processes in the North Atlantic).

In recent years there has been controversy regarding the sources of energy to the mean MOC (e.g., Wunsch and Ferrari 2004; Hughes et al. 2009; Tailleux 2009; Ferrari and Wunsch 2009). An important part of this controversy revolves around whether surface buoyancy forcing contributes energy to the circulation along with winds and tides. Turbulent mixing of the ocean interior is needed to maintain the ocean stratification in the presence of deep water formation. It is argued that such turbulence requires a source of energy, and that the only net source of energy for this turbulence is the mechanical forcing from winds and tides (Wunsch and Ferrari 2004; Ferrari and Wunsch 2009). The fact that the work of expansion and contraction associated with sources of buoyancy at the surface of the ocean is much smaller than the energy supplied by wind and tidal forces has led some to the hypothesis that surface buoyancy forcing contributes a negligible amount of energy to the flow (Kuhlbrodt et al. 2007).

Although there are also arguments that buoyancy forcing contributes to turbulent mixing (Scotti and White 2011), we do not aim to contribute here to this controversy. Instead, we focus on the energetics of MOC changes. In recent studies, energy conversions were studied in the context of the weakening of the MOC in both an idealized ocean model (Hogg et al. 2013) and a more detailed climate model (Gregory and Tailleux 2011). Here, we focus on the energy conversions associated with MOC variations on multidecadal time scales (as thought relevant to understand the AMO) using a so-called minimal model (Dijkstra 2013) of such variability, that is, a fully implicit ocean model as in Te Raa and Dijkstra (2002).

There are several frameworks that are available to study and interpret such energy conversions. We here choose the available potential energy (APE) framework, derived by Lorenz (1955) for a stratified fluid. Winters et al. (1995) showed the relevance of APE theory for turbulent stratified mixing and it was applied to the ocean context for example by Huang (1998) and Hughes et al. (2009). An overview of APE theory and its connection to the thermodynamics of fluids is provided in Tailleux (2009) and Tailleux (2013). As will be shown below, the APE framework provides a transparent connection between the propagation characteristics of the thermal Rossby mode instability mechanism and the energy conversions in the finite-amplitude oscillatory flow. Results from other frameworks, such as the recently presented dynamical potential energy (DPE) framework (Roquet 2013), are not considered here. 
In section 2, the implementation of the APE framework into the fully implicit ocean model is described. Results for steady-state flows are presented in section 3, focusing on which energy transfer processes are maintaining the steady circulation patterns. Next, in section 4 , the energetics of the multidecadal variability in the MOC will be considered with focus on the processes involved in the thermal Rossby mode. Section 5 summarizes and discusses the main results and provides the conclusions of this study.

\section{Ocean model and energy analysis}

In this section the idealized ocean model, the analysis of the energetics of the ocean flows, and the numerical methods are presented.

\section{a. Idealized ocean model}

We consider flows in a spherical sector bounded by longitudes $\phi_{w}=286^{\circ} \mathrm{E}$ and $\phi_{e}=350^{\circ} \mathrm{E}$ and by latitudes $\theta_{s}=10^{\circ} \mathrm{N}$ and $\theta_{n}=74^{\circ} \mathrm{N}$. The ocean basin has a constant depth $H$ and is bounded vertically by $z=-H$ and a nondeformable ocean-atmosphere boundary at $z=0$. The model used is the fully implicit ocean model as presented in de Niet et al. (2007) with adaptations described in that article's corrigendum. To be self-contained, the full equations and standard values of the parameters used are provided in the appendix.

The flows in the chosen domain are forced by a surface heat flux $Q_{S}$ (in $\mathrm{W} \mathrm{m}^{-2}$ ) and a wind stress field $\left(\tau^{\phi}, \tau^{\theta}\right)$ (in $\mathrm{Pa}$ ). We choose the latter as

$$
\tau^{\phi}(\theta)=-\tau_{0} \cos 2 \pi \frac{\theta-\theta_{s}}{\theta_{n}-\theta_{s}} ; \quad \tau^{\theta}=0,
$$

where $\tau_{0}$ (in $\mathrm{Pa}$ ) is a typical wind stress amplitude. The heat flux $Q_{S}$ is defined to be positive for heat flowing from the ocean to the atmosphere, and is proportional to the temperature difference between the sea surface temperature $T$ and a prescribed atmospheric temperature $T_{S}$, that is,

$$
Q_{S}=-\lambda_{T}\left(T-T_{S}\right),
$$

where $\lambda_{T}$ (in $\mathrm{W} \mathrm{m}^{-2} \mathrm{~K}^{-1}$ ) is a constant exchange coefficient. For $T_{S}$ we choose

$$
T_{S}(\theta)=T_{0}+\frac{\Delta T}{2} \cos \pi \frac{\theta-\theta_{s}}{\theta_{n}-\theta_{s}},
$$

where $T_{0}$ is a reference temperature and $\Delta T$ represents the equator-to-pole temperature difference. In section 3 below, where we analyze steady flows, we will use this restoring heat flux whereas in section 4 , where the variability is considered, we will use a diagnosed heat flux from a steady-state model solution and no restoring term. Both wind and buoyancy forcing are distributed as a body forcing over the upper layer of the ocean having a depth $H_{m}$.

Temperature differences in the ocean cause density differences according to

$$
\rho=\rho_{0}\left[1-\alpha_{T}\left(T-T_{0}\right)\right],
$$

where $\alpha_{T}$ is the thermal expansion coefficient and $\rho_{0}$ a reference density.

We use the Boussinesq and hydrostatic approximations with horizontal $\left(A_{H}, K_{H}\right)$ and vertical $\left(A_{V}, K_{V}\right)$ mixing coefficients of momentum and heat, respectively. As mentioned in the appendix we use convective adjustment where the vertical mixing coefficient of heat $K_{V}$ is written as

$$
K_{V}=K_{V}^{0}+\mathcal{F}\left(N_{b}^{2}\right) K_{V}^{c} ; \quad N_{b}^{2}=-\frac{g}{\rho_{0}} \frac{\partial \rho}{\partial z},
$$

where $\mathcal{F}$ is a mixing profile function. The other mixing coefficients are assumed constant.

\section{b. Energy balances}

In the analysis below, we will use the Hughes et al. (2009) interpretation of the APE framework, which focuses only on the mechanical energy balances. This interpretation simplifies the energetic pathways by concentrating on buoyancy production/dissipation in the absence of internal energy constraints. A more comprehensive interpretation of the energetics, which is consistent with the thermodynamics of stratified flows, can be found in Tailleux (2009). The simplified interpretation is adequate for flow problems that involve buoyancy forces and wind stress as is the case here. However, it leads to subtle differences in the physical interpretation of the individual terms in the equations below compared with Tailleux (2009); for convenience both will be mentioned and interested readers can consult Tailleux (2009) for more details.

When the momentum equations from the model, Eqs. (A1a) and (A1b) in the appendix, are multiplied by the velocity vector and the resulting equations are averaged over the flow domain, we obtain the mechanical energy balance [using notation similar to that in Hughes et al. (2009)]

$$
\frac{d E_{k}}{d t}=\Phi_{T}-\Phi_{z}+\Phi_{w}
$$

where

$$
E_{k}=\frac{1}{2 V} \int_{V}\left(u^{2}+v^{2}\right) d^{3} x
$$




$$
\Phi_{T}=\frac{1}{V} \int_{V} u\left[A_{V} \frac{\partial^{2} u}{\partial z^{2}}+A_{H} L_{u}(u, v)\right]+v\left[A_{V} \frac{\partial^{2} v}{\partial z^{2}}+A_{H} L_{v}(u, v)\right] d^{3} x
$$

$$
\begin{aligned}
\Phi_{z} & =\frac{g}{\rho_{0} V} \int_{V} \rho w d^{3} x, \\
\Phi_{w} & =\frac{1}{\rho_{0} H_{m} V} \int_{V}\left(u \tau^{\phi}+v \tau^{\theta}\right) \mathcal{G}(z) d^{3} x,
\end{aligned}
$$

with $V$ being the volume of the ocean basin and $g$ the gravitational acceleration. The above quantities are the kinetic energy $E_{k}$, the dissipation $\Phi_{T}$, the rate of conversion between potential and kinetic energy $\Phi_{z}$, and the power input from wind stress $\Phi_{w}$. Also, $L_{u}$ and $L_{v}$ represent the horizontal friction terms in spherical polar coordinates and $\mathcal{G}(z)$ describes the distribution of surface momentum and buoyancy fluxes across the uppermost layer (see the appendix for details).

By multiplying the temperature equation by $z \rho_{0} g \alpha_{T}$ and using (4), the potential energy balance follows as

$$
\frac{d E_{p}}{d t}=\Phi_{z}+\Phi_{d 1}+\Phi_{b 1}
$$

with

$$
\begin{aligned}
E_{p}= & \frac{g}{\rho_{0} V} \int_{V} \rho z d^{3} x, \\
\Phi_{d 1}= & -\frac{K_{V}^{0} g}{\rho_{0} V} \int_{S}\left(\rho_{\text {top }}-\rho_{\text {bot }}\right) d^{2} x, \\
\Phi_{b 1}= & \frac{g}{\rho_{0} V} \int_{V} z\left[K_{H} \nabla_{H}^{2} \rho+\frac{\partial}{\partial z}\left(K_{V} \frac{\partial \rho}{\partial z}\right)\right] d^{3} x \\
& -\Phi_{d 1}+\frac{g}{\rho_{0} V} \int_{V} z Q_{\rho} \mathcal{G}(z) d^{3} x,
\end{aligned}
$$

where $E_{p}$ is the gravitational potential energy, $S$ the area of the ocean surface, and $\rho_{\text {top }}=\rho(\phi, \theta, z=0, t)$ and $\rho_{\text {bot }}=\rho(\phi, \theta, z=-H, t)$. In the Hughes et al. (2009) interpretation, the term $\Phi_{d 1}$ represents the rate of potential energy change associated with the lifting of the center of mass of the fluid column by the background vertical diffusion. In the Tailleux (2009) interpretation, it is the conversion rate between internal energy and gravitational potential energy. The last term in $\Phi_{b 1}$ is the buoyancy power input due to boundary fluxes with $Q_{\rho}=$ $-\alpha_{T} Q_{S} /\left(C_{p} H_{m}\right)$, where $C_{p}$ is a constant heat capacity. This term is associated with an external source of internal energy, as explained by Tailleux (2009); for example, one requires internal energy to cool or heat the fluid and thereby create buoyancy differences.
In a stratified fluid, the amount of potential energy available to be released to kinetic energy is determined by defining a relevant background state with minimum potential energy (Winters et al. 1995). This background state is reached by adiabatic adjustment under gravity, with all other forcing removed. The background state is defined by the field $z_{*}(\phi, \theta, z, t)$, which is the depth of the fluid element at $(\phi, \theta, z)$ in the reference configuration. The background potential energy $E_{b}$ is then

$$
E_{b}=\frac{g}{\rho_{0} V} \int_{V} z_{*} \rho d^{3} x
$$

and the rate of change of background potential energy $E_{b}$ is given by

$$
\frac{d E_{b}}{d t}=-\Phi_{b 2}+\Phi_{d 2}
$$

Here, the loss of background potential energy by surface forcing, $\Phi_{b 2}$, and the gain of background potential energy by mixing $\Phi_{d 2}$ are

$$
\begin{aligned}
\Phi_{d 2} & =\frac{g}{\rho_{0} V} \int_{V} z_{*}\left[K_{H} \nabla_{H}^{2} \rho+\frac{\partial}{\partial z}\left(K_{V} \frac{\partial \rho}{\partial z}\right)\right] d^{3} x, \\
\Phi_{b 2} & =-\frac{g}{\rho_{0} V} \int_{V} z_{*} Q_{\rho} \mathcal{G}(z) d^{3} x .
\end{aligned}
$$

The field $z_{*}$ is calculated by a sorting scheme, similar to that used in Hughes et al. (2009).

Using (5), the energy conversion rates $\Phi_{b 1}$ and $\Phi_{d 2}$ can be written as

$$
\Phi_{b 1}=\Phi_{b 1}^{0}+\Phi_{b 1}^{c} ; \quad \Phi_{d 2}=\Phi_{d 2}^{0}+\Phi_{d 2}^{c},
$$

where the superscript 0 refers to the background value $K_{V}^{0}$ and the superscript $c$ refers to convective adjustment.

The evolution equation for the available potential energy $E_{a}=E_{p}-E_{b}$ is given by

$$
\frac{d E_{a}}{d t}=\Phi_{z}+\Phi_{b}-\Phi_{d}+\Phi_{c a}
$$

with

$$
\Phi_{b}=\Phi_{b 1}^{0}+\Phi_{b 2} ; \quad \Phi_{d}=\Phi_{d 2}^{0}-\Phi_{d 1} ; \quad \Phi_{c a}=\Phi_{b 1}^{c}-\Phi_{d 2}^{c} .
$$




\section{c. Numerical implementation}

The model equations as given in the appendix are discretized in space using a second-order accurate control volume discretization method on a staggered Arakawa B grid in the horizontal with $i=1, \ldots, N, j=1, \ldots, M$, and a $C$ grid in the vertical with $k=1, \ldots, L$. The spatially discretized model equations can be written in the form

$$
\mathbf{M} \frac{d \mathbf{x}}{d t}=\mathbf{F}(\mathbf{x})=\mathbf{L}(\mathbf{x})+\mathbf{N}(\mathbf{x}, \mathbf{x}),
$$

where the state vector $\mathbf{x}$ contains the unknowns $(u, v, w$, $p, T)$ at each grid point and hence has dimension $d=5 \times$ $N \times M \times L$. The operators $\mathbf{M}$ and $\mathbf{L}$ are linear and $\mathbf{N}$ represents the nonlinear terms in the equations. In all results below, we take equidistant grids, with $N=$ $M=L=16$.

In the results presented in section 3, we determine steady solutions directly versus a control parameter in the model using a pseudoarclength continuation technique. From (16) it follows that steady-state solutions can be found from the nonlinear algebraic equations

$$
\mathbf{F}(\mathbf{x}, \mathbf{p})=0 .
$$

Here the parameter dependence of the equations is made explicit through the $p$-dimensional vector of parameters $\mathbf{p}$ and hence $\mathbf{F}$ is a nonlinear mapping from $\mathbf{R}^{d+p} \rightarrow \mathbf{R}^{d}$. To determine branches of steady solutions of Eq. (17) as one of the parameters, say $\mu$, is varied, the pseudoarclength method suggested in Keller (1977) is used. The branches $[\mathbf{u}(s), \mu(s)]$ are parameterized by an arclength parameter $s$. An additional equation is obtained by "normalizing" the tangent

$$
\dot{\mathbf{x}}_{0}^{T}\left(\mathbf{x}-\mathbf{x}_{0}\right)+\dot{\mu}_{0}\left(\mu-\mu_{0}\right)-\Delta s=0,
$$

where $\left(\mathbf{x}_{0}, \mu_{0}\right)$ is an analytically known starting solution or a previously computed point on a particular branch and $\Delta s$ is the step length. Euler-Newton continuation is used to solve the system of Eqs. (17) and (18).

For the results in section 4, we use a fully implicit Crank-Nicholson (Atkinson 1989) time integration scheme (which is second order in the time step $\Delta t$ ). Using a time index $n$, this scheme becomes

$$
\mathbf{M} \frac{\mathbf{x}^{n+1}-\mathbf{x}^{n}}{\Delta t}=\frac{1}{2}\left[\mathbf{F}\left(\mathbf{x}^{n}\right)+\mathbf{F}\left(\mathbf{x}^{n+1}\right)\right] .
$$

The equations for $\mathbf{x}^{n+1}$ are solved again by the NewtonRaphson technique and lead to the same type of numerical problems as that for the steady-state computation. In all
TABLE 1. Values of fixed parameters used in the numerical calculations in section 3 and 4 . In the table, $\tau_{T}=\rho_{0} C_{p} H_{m} / \lambda_{T}$ is the restoring time scale for temperature used when restoring conditions are applied (section 3 ).

\begin{tabular}{ll}
\hline \hline $2 \Omega=1.4 \times 10^{-4}\left(\mathrm{~s}^{-1}\right)$ & $r_{0}=6.4 \times 10^{6}(\mathrm{~m})$ \\
$\left.C_{p}=4.2 \times 10^{3}\left[\mathrm{~J}^{-1} \mathrm{~kg}^{-1}\right)^{-1}\right]$ & $\tau_{T}=7.5 \times 10^{1}(\mathrm{days})$ \\
$\alpha_{T}=1.0 \times 10^{-4}\left(\mathrm{~K}^{-1}\right)$ & $\rho_{0}=1.0 \times 10^{3}\left(\mathrm{~kg} \mathrm{~m}^{-3}\right)$ \\
$A_{H}=1.6 \times 10^{5}\left(\mathrm{~m}^{2} \mathrm{~s}^{-1}\right)$ & $A_{V}=1.0 \times 10^{-3}\left(\mathrm{~m}^{2} \mathrm{~s}^{-1}\right)$ \\
$K_{H}=1.0 \times 10^{3}\left(\mathrm{~m}^{2} \mathrm{~s}^{-1}\right)$ & $K_{V}^{0}=1.0 \times 10^{-4}\left(\mathrm{~m}^{2} \mathrm{~s}^{-1}\right)$ \\
$H=4.0 \times 10^{3}(\mathrm{~m})$ & $H_{m}=2.5 \times 10^{2}(\mathrm{~m})$ \\
$T_{0}=15.0\left({ }^{\circ} \mathrm{C}\right)$ & $\tau_{0}=0.1(\mathrm{~Pa})$ \\
\hline
\end{tabular}

results in section 4 , we take a time step $\Delta t$ of approximately 1 month, which gives sufficiently accurate solutions.

\section{Steady flows}

In this section, steady flows will be computed under restoring boundary conditions, that is, using the surface heat flux (2) and using the parameters in Table 1. According to (3), the parameter $\Delta T$ represents the equatorto-pole temperature difference and we will use it here as one of the control parameters. Using continuation, we first compute a branch of steady solutions by varying $\Delta T$ in (3) from $0^{\circ}$ to $20^{\circ} \mathrm{C}$ while keeping $\tau_{0}=0.0 \mathrm{~Pa}$. The maximum strength of the MOC (over the whole domain) is shown in Fig. 1a and follows a well-known $1 / 3$ power-law scaling. This relation has been well established in single hemispheric models (Den Toom and Dijkstra 2011) and can be explained by dominant geostrophic momentum balances and an advection-diffusion balance for the thermocline in the model.

For $\Delta T=20^{\circ} \mathrm{C}$ the surface heat flux $Q_{S}$ is diagnosed and plotted in Fig. 1b, with positive values when heat is going into the ocean. As can be seen, most heat is extracted from the ocean over the broad western boundary current in the model with a maximum value of about $160 \mathrm{~W} \mathrm{~m}^{-2}$. We will use this surface heat flux $Q_{S}$ in section 4 when computing multidecadal oscillations in these flows under prescribed flux conditions. In this section, however, the terms in the energy balances are computed with the restoring heat flux given by (2).

In the fully implicit ocean model, each term in the equations is represented by a local operator (see Dijkstra 2005 , chapter 4) such that the contribution from convective adjustment (the terms $\Phi_{b 1}^{c}$ and $\Phi_{d 2}^{c}$ ) can be explicitly determined. The integrals in the energy balances can be calculated up to Newton-Raphson tolerance error. As a consequence, the energy balances can also be closed at the same accuracy (a relative error of $10^{-6}$ ).

In the kinetic energy balance for $\Delta T=20^{\circ} \mathrm{C}$, the dissipation $\Phi_{T}$ is exactly balanced by $\Phi_{z}$ (see Fig. 2b for $\tau_{0}=0.0 \mathrm{~Pa}$ ). This means that for the surface temperature 


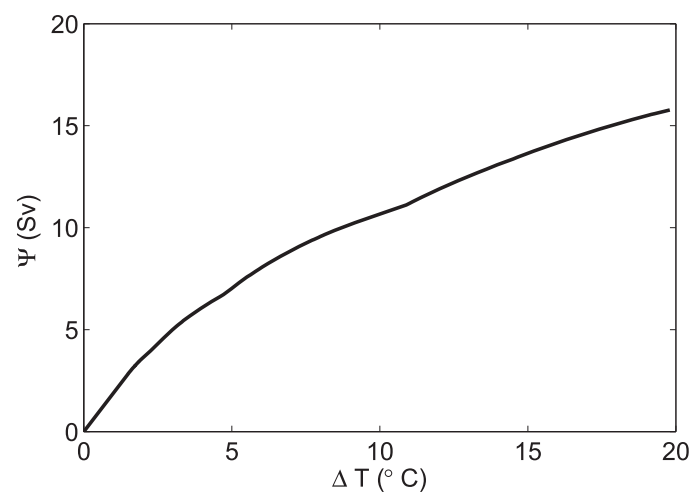

(a)

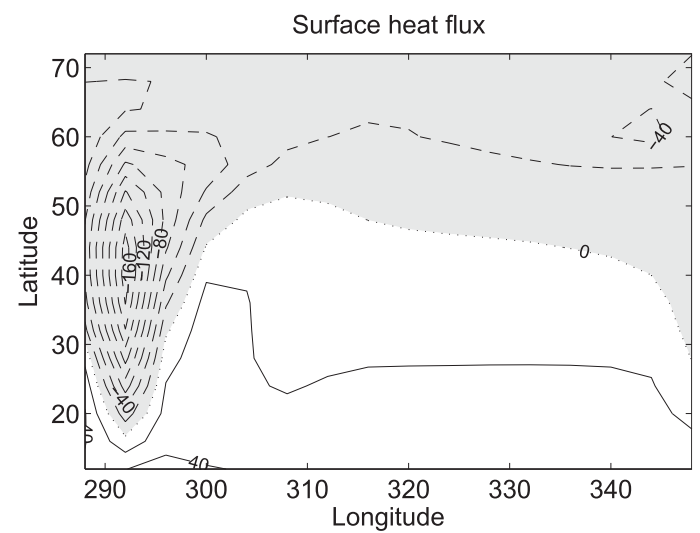

(b)

FIG. 1. (a) Bifurcation diagram showing the maximum value of the $\mathrm{MOC}(\Psi)$ vs the restoring temperature difference $\Delta T$ for the case without wind stress $\left(\tau_{0}=0.0 \mathrm{~Pa}\right)$. (b) Diagnosed heat flux $\left(\mathrm{W} \mathrm{m}^{-2}\right)$ at the endpoint of the curve in (a), that is, for $\Delta T=20^{\circ} \mathrm{C}$.

gradient to drive the flow, a conversion of available potential energy to kinetic energy is needed. The background potential energy $E_{b}$ is increased both by diapycnal mixing (term $\Phi_{d 2}^{0}$ ) as well as convective adjustment (term $\Phi_{d 2}^{c}$ ), although the latter contribution is small (Fig. 2c for $\tau_{0}=0.0 \mathrm{~Pa}$ ). In Fig. $2 \mathrm{~d}$ (for $\tau_{0}=0.0 \mathrm{~Pa}$ ), it can be seen how this is accomplished: the input of available potential
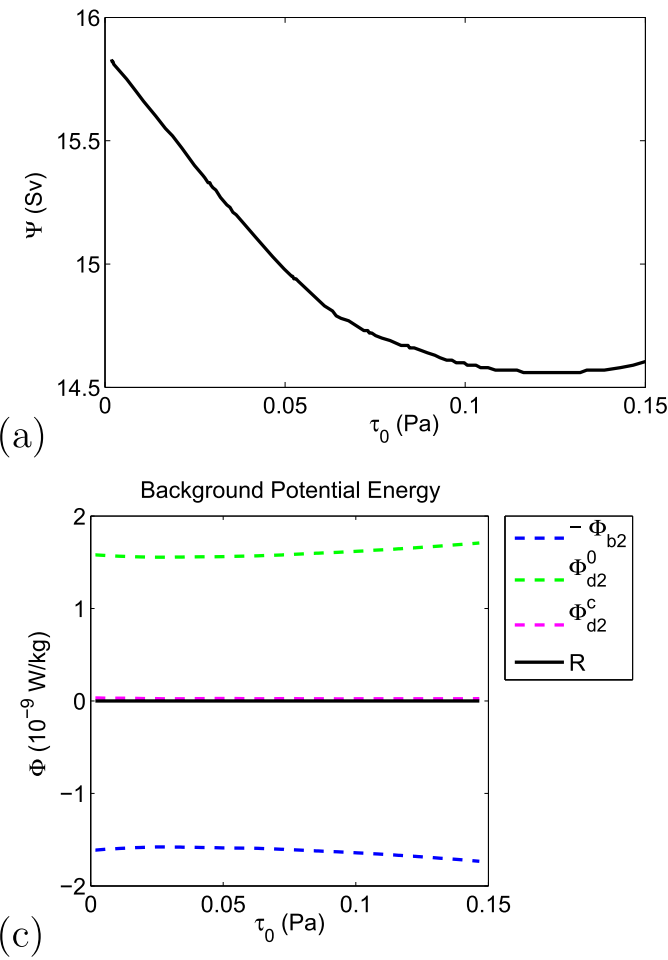

energy due to the surface buoyancy forcing $\Phi_{b}$ is not completely compensated by the loss of available potential energy due to mixing. The negative value of $\Phi_{z}$ arises therefore as a residual in the available potential energy balance.

In the APE framework there are currently two interpretation of the term $\Phi_{b}$. In the one by Hughes et al. (2009)

FIG. 2. (a) Bifurcation diagram showing the strength of the MOC vs $\tau_{0}$ for $\Delta T=20^{\circ} \mathrm{C}$. (b) Terms in the kinetic energy equation. (c) Terms in the background potential energy equation. (d) Terms in the available potential energy equation. The term $R$ is the residual in the balance.
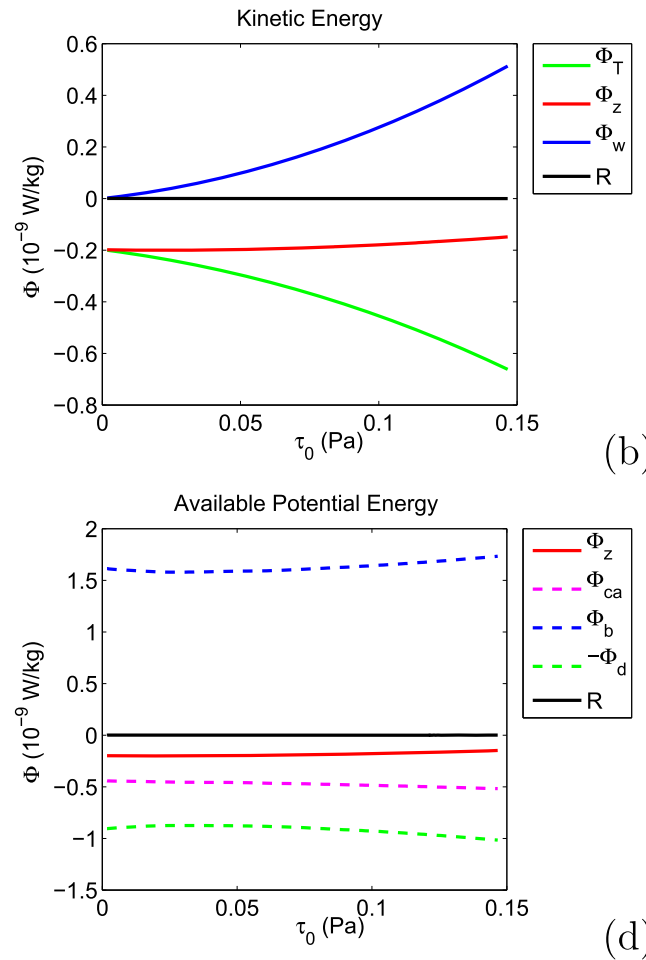

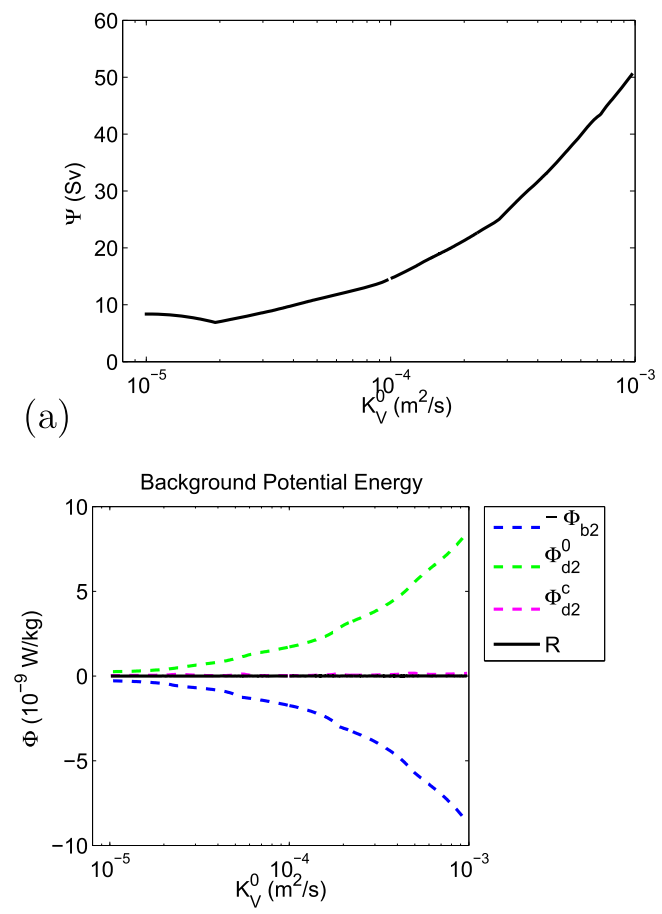

(c)
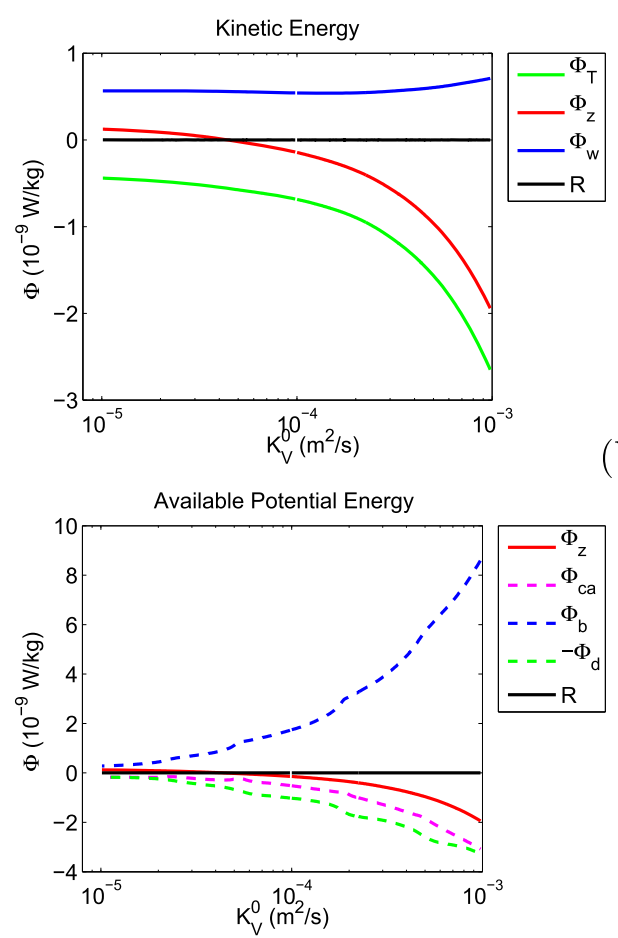

(d)

FIG. 3. (a) Bifurcation diagram showing the strength of the MOC vs $K_{V}^{0}$ for $\tau_{0}=0.15 \mathrm{~Pa}$ and $\Delta T=20^{\circ} \mathrm{C}$. (b) Terms in the kinetic energy equation. (c) Terms in the background potential energy equation. (d) Terms in the available potential energy equation. The term $R$ is the residual in the balance.

used here, $\Phi_{b}$ acts as a catalyst for the release of background potential energy, which is otherwise created by diapycnal mixing. In the interpretation by Tailleux (2009), $\Phi_{b}$ is interpreted as a conversion term between internal and mechanical energy, which gives a physical basis for saying that the surface buoyancy fluxes "drive" the overturning circulation. In both interpretations, however, the surface buoyancy fluxes induce energy conversions toward APE that are responsible for the kinetic energy associated with the overturning flow.

We next consider the influence of the wind stress (1) on the overturning circulation and the energy balances and use $\tau_{0}$ as a control parameter. From the endpoint of Fig. 1a (for $\tau_{0}=0$ ), a branch of steady solutions is computed by varying $\tau_{0}$ from 0 to $0.15 \mathrm{~Pa}$. The strength of the MOC and the terms in the energy equations are shown in Fig. 2. The maximum strength of the MOC only slightly changes due to the presence of the wind stress. It decreases down to $\tau_{0}=0.12 \mathrm{~Pa}$ and then slightly increases again up to $\tau_{0}=0.15 \mathrm{~Pa}$ (Fig. 2a). The power due to the wind stress field $\Phi_{w}$ increases with $\tau_{0}$ and together with the available potential energy to kinetic energy conversion term $\Phi_{z}$ balances the dissipation $\Phi_{T}$ in the model (Fig. 2b). The wind stress causes Ekman pumping and hence deformation of isopycnals. These changes in stratification affect the residual in the available potential energy balance and $\Phi_{z}$ is reduced (becomes less negative). For the highest value of the wind stress, the value of $\Phi_{z}$ is still negative, which indicates that in this case both buoyancy and wind affect the strength of the MOC.

From the endpoint of Fig. 2a (at $\tau_{0}=0.15 \mathrm{~Pa}$ ), a branch of steady solutions is computed by varying $K_{V}^{0}$ from $10^{-5}$ to $10^{-3} \mathrm{~m}^{2} \mathrm{~s}^{-1}$. The MOC strength increases with $K_{V}^{0}$ over a large interval (Fig. 3); only at small values of $K_{V}^{0}$ does the overturning slightly decrease with $K_{V}^{0}$. The kinetic energy balance reflects this change in behavior as $\Phi_{z}$ changes sign just at the point where the MOC is minimal. This indicates that at small values of $K_{V}^{0}$ there is a net (although small) rate of transfer of kinetic energy to potential energy in the flow $\left(\Phi_{z}>0\right)$. Because $K_{V}^{0}$ decreases, the flow induced by Ekman pumping becomes larger than that due to buoyancy gradients, which is reflected in an increase of the maximum MOC with decreasing $K_{V}^{0}$. When a value of the meridional overturning streamfunction is used below the Ekman layer (not shown), it does not change with decreasing $K_{V}^{0}$.

In the calculations of Hughes et al. (2009) a nonhydrostatic two-dimensional ocean model is used and 
several terms in the available potential energy balance are calculated for equilibrium flows. Over the interval $K_{V}$ of $10^{-4}-10^{-3} \mathrm{~m}^{2} \mathrm{~s}^{-1}$ (which overlaps with the results here), they find (without wind) that $\Phi_{z}<0$, in agreement with the results here. In the recent results of Saenz et al. (2012), both the effects of wind and buoyancy are considered for an idealized three-dimensional configuration in the Massachusetts Institute of Technology GCM (MITgcm). The term $\Phi_{z}$ [C(KE, APE) in their paper] becomes positive at larger wind stress for the case of $K_{V}=10^{-5} \mathrm{~m}^{2} \mathrm{~s}^{-1}$. The results for the steady-state model here are hence consistent with previous analyses of the energy balances in more sophisticated models.

\section{Multidecadal variability}

We next go back to the thermal-only case (no wind stress); the surface heat flux $Q_{S}$ in Fig. $1 \mathrm{~b}$ is exactly the flux needed to maintain the steady solution [which was computed under the restoring heat flux (2)] at the endpoint of the curve in Fig. $1 \mathrm{a}\left(\Delta T=20^{\circ} \mathrm{C}\right)$. In this section, the heat flux $Q_{S}$ is used under prescribed flux conditions (no restoring) to start a time integration with the solution at the end point of the branch in Fig. 1a as initial condition.

The transient flow development is plotted in Fig. 4a over a time interval of 500 years. As is well known (Te Raa and Dijkstra 2002), the steady solution under prescribed flux conditions is unstable to oscillatory disturbances (although it is stable under restoring conditions). After a while, variability in the MOC on a multidecadal time scale appears with a peak-to-peak amplitude of about $8 \mathrm{~Sv}\left(1 \mathrm{~Sv} \equiv 10^{6} \mathrm{~m}^{3} \mathrm{~s}^{-1}\right)$. The patterns of the MOC (Fig. 4) at four different times during the oscillation indicate a weakening (Fig. 4b) and strengthening (Fig. 4d) of the MOC. During the weakening of the MOC, the sinking latitude shifts southward whereas during the strengthening it shifts northward.

The temperature anomaly fields are plotted as the difference fields $T-T_{S}$ where $T=T(\phi, \theta, z=0, t)$ is the SST of the model solution and $T_{S}$ the background temperature (3). For four different times during an oscillation cycle, $T-T_{S}$ is plotted in Fig. 5, which clearly demonstrates the northwestward propagation of the SST, in particular in the western half of the domain. The weak and strong MOC states coincide with the small zonal SST gradient in Fig. 5a and strong zonal SST gradient in Fig. $5 \mathrm{c}$ (note that $T_{S}$ is zonally independent).

The underlying mechanism of the instability leading to the multidecadal variability here is known to be caused by a thermal Rossby mode that destabilizes the background MOC (Te Raa and Dijkstra 2002). A sketch of the physics of the thermal Rossby mode is provided with help of Fig. 6. A warm anomaly in the north-central part of the basin causes a positive meridional perturbation temperature gradient, which induces-via the thermal wind balance-a westward zonal surface flow (Fig. 6a). The anomalous anticyclonic circulation around the warm anomaly causes southward (northward) advection of cold (warm) water to the east (west) of the anomaly, resulting in westward phase propagation of the warm anomaly. Because of this westward propagation, the zonal perturbation temperature gradient becomes negative, inducing a negative surface meridional flow (Fig. 6b). The resulting upwelling (downwelling) perturbations along the northern (southern) boundary cause a negative meridional perturbation temperature gradient, inducing a positive zonal surface flow, and the second half of the oscillation starts. The crucial elements in this oscillation mechanism are the phase difference between the zonal and meridional surface flow perturbations, and the westward propagation of the temperature anomalies ( $\mathrm{Te}$ Raa and Dijkstra 2002).

In the finite-amplitude oscillatory flow (Fig. 4) it is now interesting what energy conversion processes take place and whether we can connect this to the properties of the thermal Rossby mode. As the field $z_{*}$ plays an essential role in the terms of the available potential energy balance, surface values and a latitudinal section (at the central longitude of the basin) of $z_{*}$ are plotted in Fig. 7 for four different times. From the southern boundary to $50^{\circ} \mathrm{N}, z_{*}$ is zonally and meridionally homogeneous and increases approximately linearly with depth. In this region of the domain, the flow is strongly stably stratified. In the sinking region, values of $z_{*}$ show strong meridional gradients while being near vertically homogeneous. In the sinking regions, there is a nearneutral stratification and hence fluid elements at the surface will be displaced to significant depth in the background configuration. A very similar equilibrium distribution of $z_{*}$ was found in Saenz et al. (2012) with large values of $z_{*}$ in sinking regions (in particular in the Southern Ocean) and values being approximately latitudinally homogeneous outside the sinking regions.

The rates of energy transfer characterizing the multidecadal variability are shown in Figs. 8a-c, in which now the time derivative of each of the energy quantities is plotted (dashed black lines). In Fig. 8c, all terms in the available potential energy balance are plotted such that any negative value indicates a sink of available potential energy and any positive value a source. Convective adjustment as well as vertical mixing always acts as a sink of available potential energy.

The main issue is how the term $\Phi_{z}$ arises as it clearly drives the oscillation according to Fig. 8a. The interpretation of cause and effect of the energetic balance 


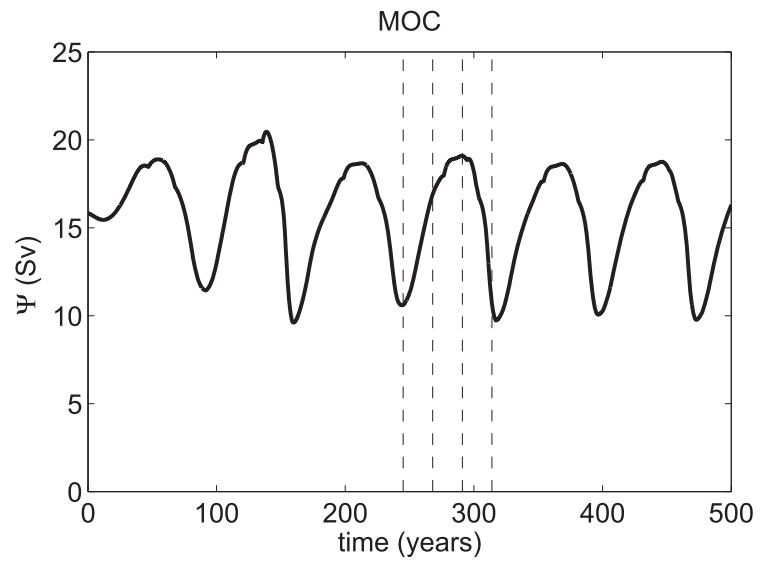

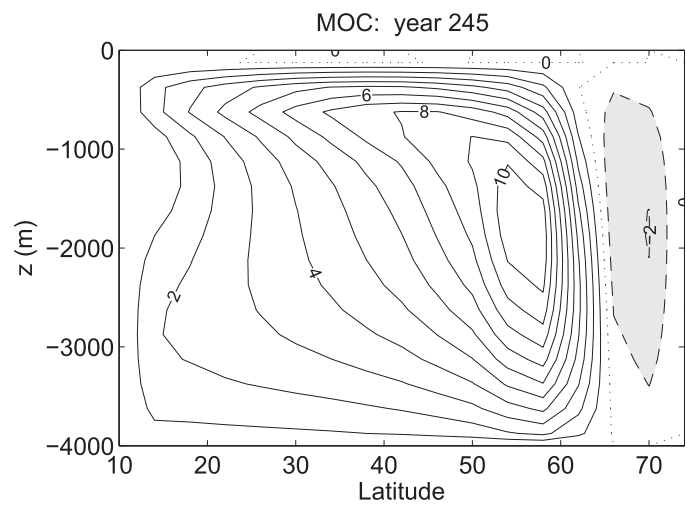

(b)

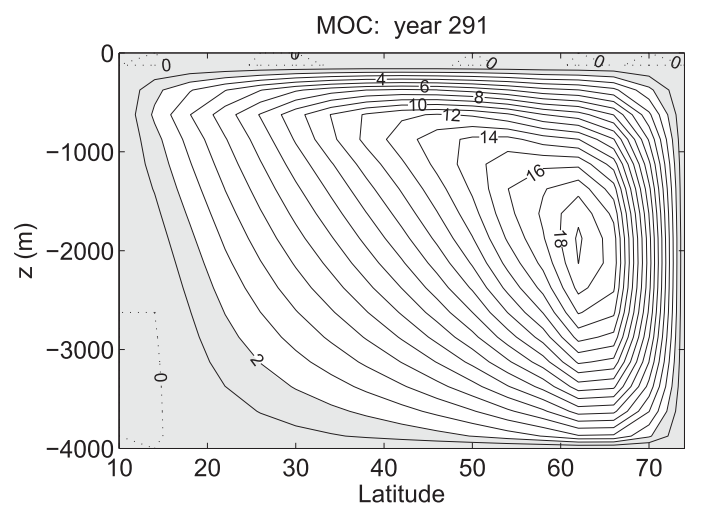

(d)

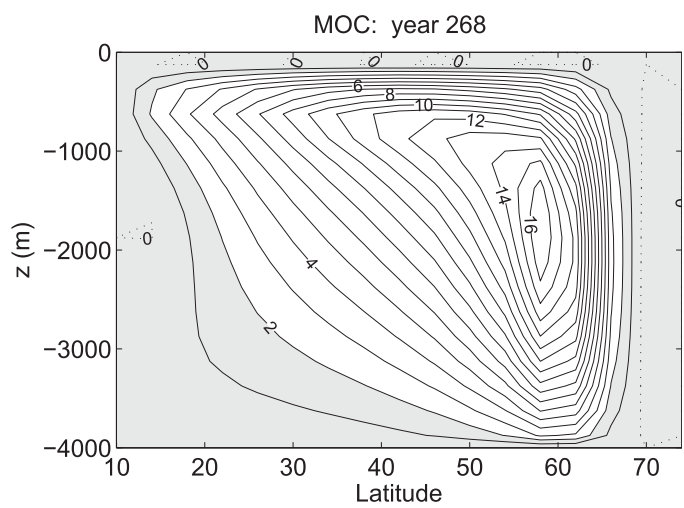

(c)

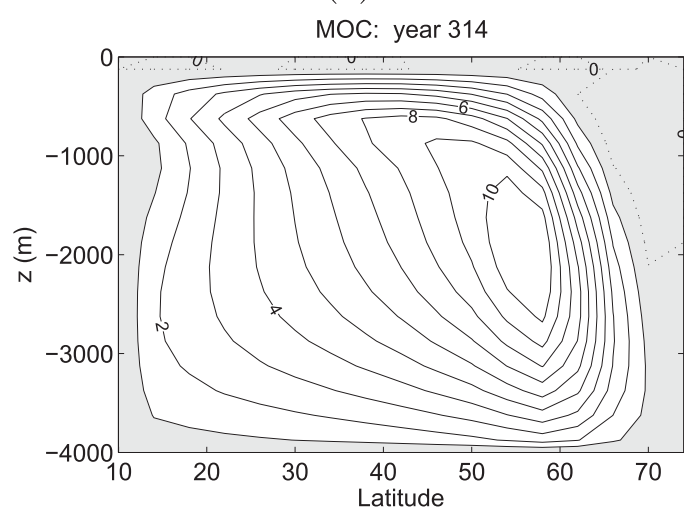

(e)

FIG. 4. (a) Strength of the MOC vs time (in yr), and MOC patterns at four different times: (b) $245 \mathrm{yr}$ (MOC minimum), (c) $268 \mathrm{yr}$, (d) $291 \mathrm{yr}$ (MOC maximum), and (e) $314 \mathrm{yr}$.

of the oscillations in Fig. 8 is, however, complicated because both $\Phi_{z}$ and $d E_{a} / d t$ can adjust to the variation of the energy fluxes caused by the other processes and it is therefore difficult to understand the phase differences between the different terms. When the MOC is weak (year 245, first vertical dashed line), the production of APE due to the surface buoyancy forcing $\left(\Phi_{b 2}\right)$ is larger than all sinks of APE, resulting in a positive tendency of
APE leading to an increase of $-\Phi_{z}$, and hence the MOC strength increases. As the sinking region moves northward, large negative values of $z *$ shift northward and hence $\Phi_{b 2}$ has decreased already in year 268 (second vertical dashed line) while the MOC is still increasing. In year 291 (third vertical dashed line) the MOC is maximum but the APE tendency is already negative, leading to a weakening of the MOC. 


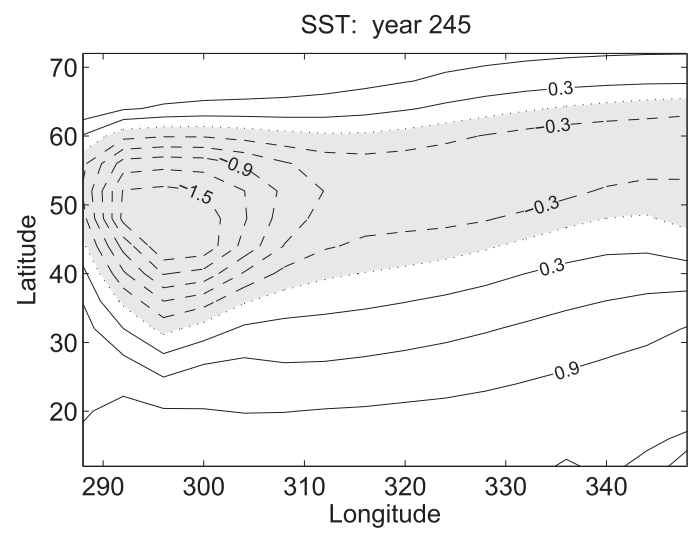

(a)

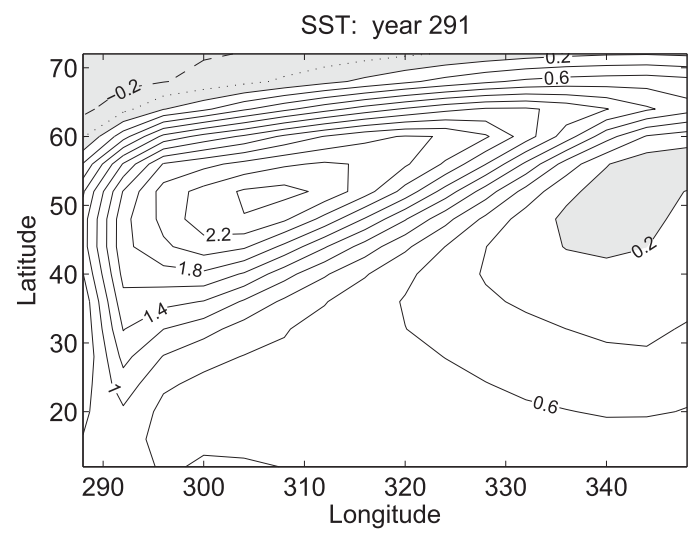

(c)

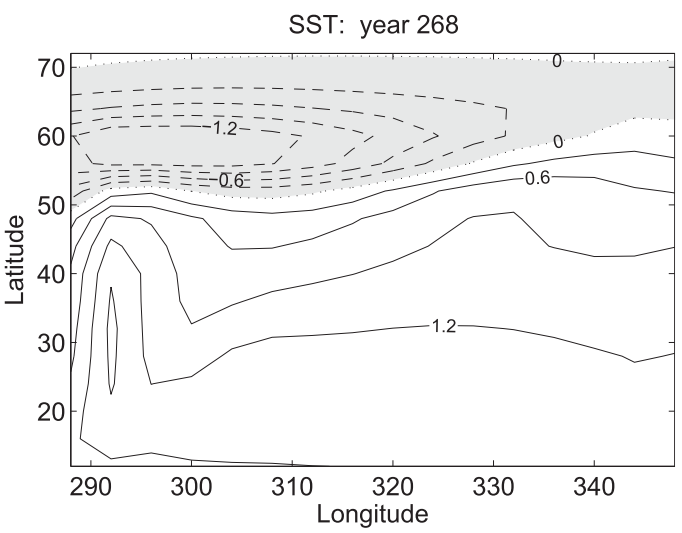

(b)

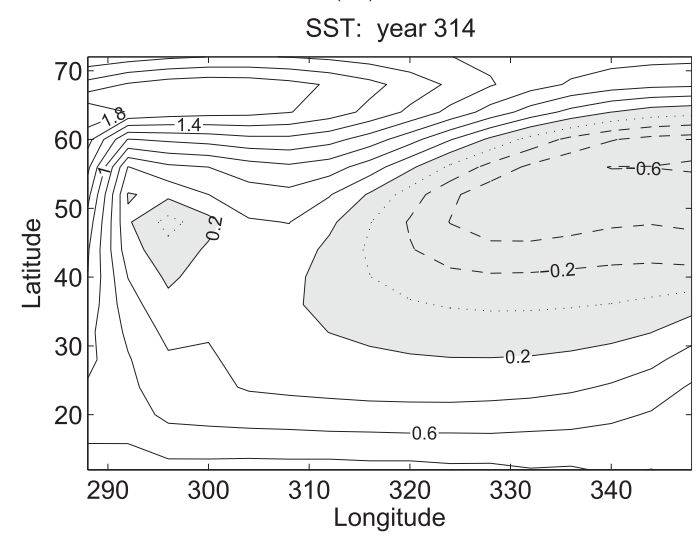

(d)

FIG. 5. SST anomaly patterns (with respect to the restoring temperature $T_{S}$ ) at four different times: (a) 245, (b) 268, (c) 291, and (d) $314 \mathrm{yr}$.

As shown by Gregory and Tailleux (2011), the local conversion between kinetic energy and (available) potential energy can be deduced by the field $-\mathbf{u}_{h} \cdot \nabla_{h} p$, where the subscript $h$ indicates the horizontal component. Since the volume integral of $\mathbf{u} \cdot \nabla p$ is zero, it can be easily shown that

$$
-\Phi_{z}=-\frac{g}{\rho_{0} V} \int_{V} \rho w d^{3} x=\frac{1}{\rho_{0} V} \int_{V}-\mathbf{u}_{h} \cdot \nabla_{h} p d^{3} x
$$

To determine the regions where APE is actually a source of kinetic energy and how this compares with

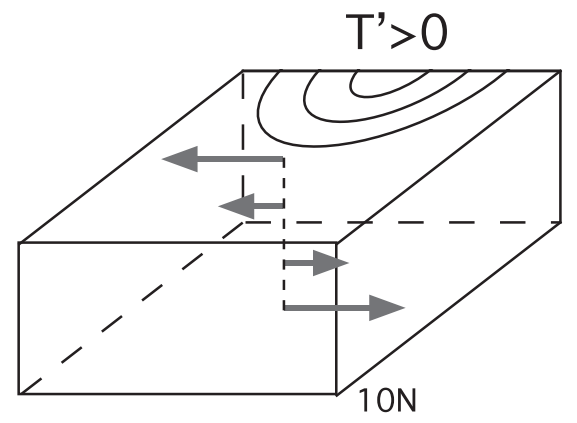

$70 \mathrm{~N}$

(a)

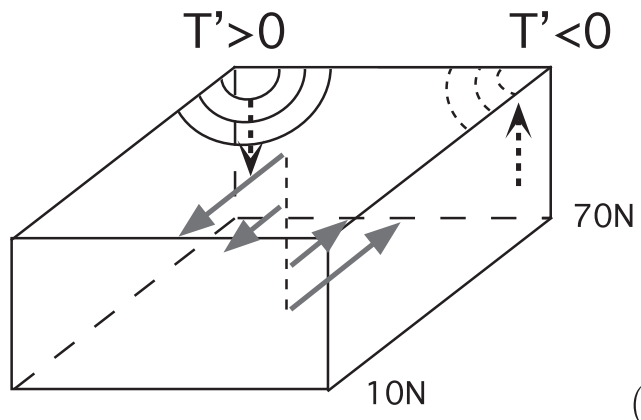

FIG. 6. Schematic diagram of the oscillation mechanism associated with the multidecadal mode caused by the westward propagation of the temperature anomalies, indicated here by $T^{\prime}$. The phase difference between (a) and (b) is about a quarter period. See text and Te Raa and Dijkstra (2002) for a further explanation. 


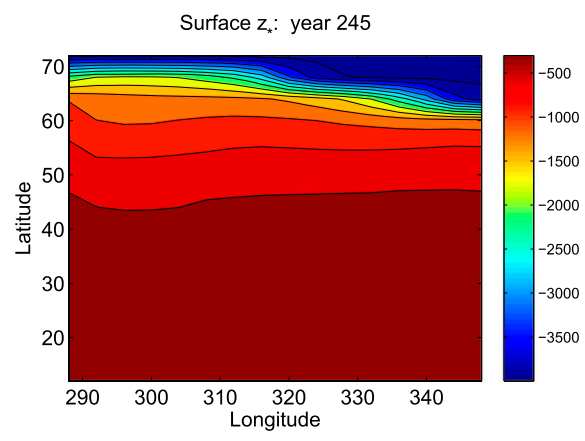

(a)
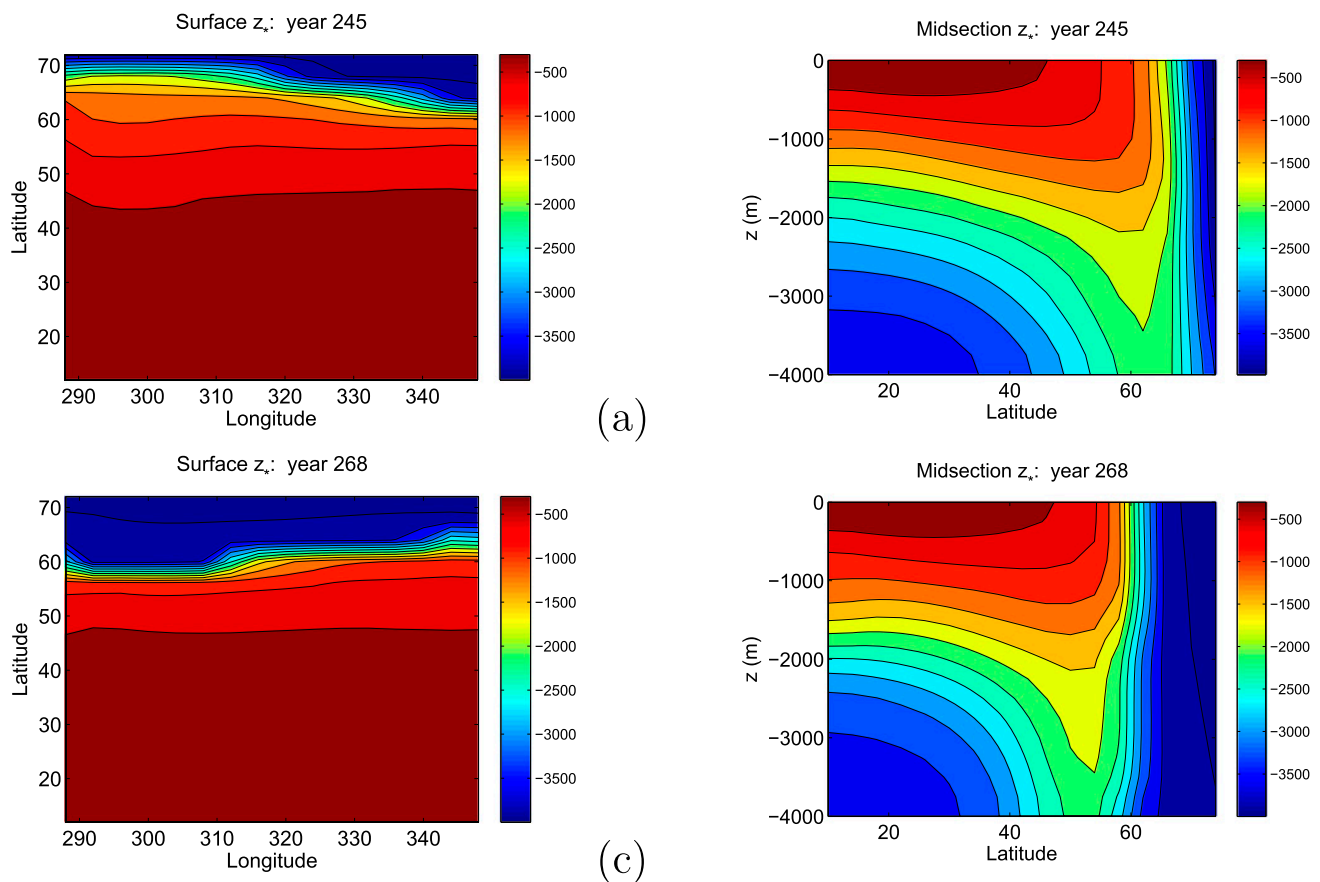

(c)
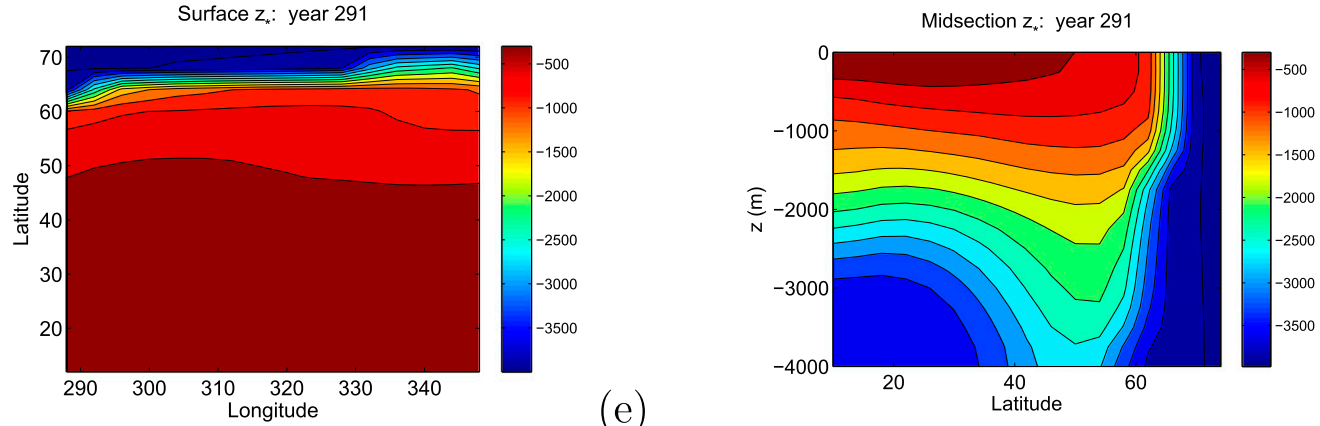

(d)

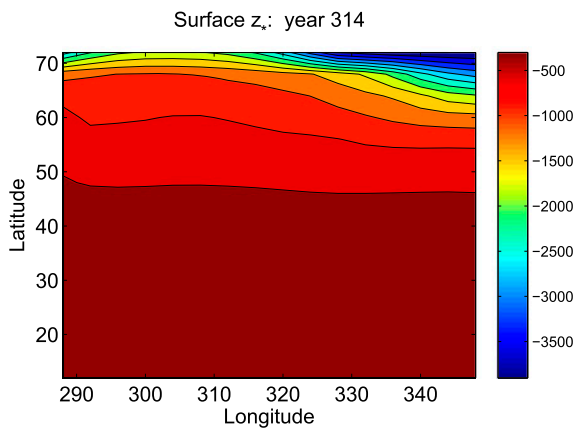

(e)

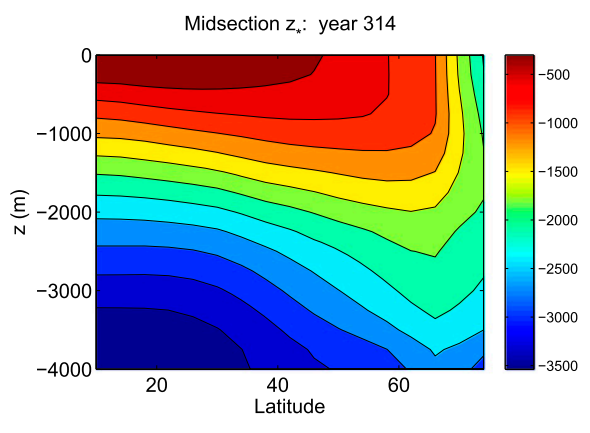

(g)

FIG. 7. Surface values of $z *$ and section of $z_{*}$ at $\phi=318^{\circ} \mathrm{E}$ at four different times: (a),(b) 245 , (c),(d) 268 , (e),(f) 291 , and (g),(h) $314 \mathrm{yr}$.

the APE production rate, we plot in Figs. 9a,c,e,g the APE production field $z_{*}(z=0) Q_{S}$ (in $\left.\mathrm{W} \mathrm{m}^{-1}\right)$, which appears in the definition of $\Phi_{b 2}$, and in Figs. $9 \mathrm{~b}, \mathrm{~d}, \mathrm{f}, \mathrm{h}$ the vertical integral of $-\mathbf{u}_{h} \cdot \nabla_{h} p\left(\right.$ in $\left.\mathrm{W} \mathrm{m}^{-2}\right)$. APE production mainly occurs in the northern regions of the domain, where cold water is cooled and hence the equilibrium depth $z_{*}$ is located at large depths. Most of the conversion between APE and kinetic energy, however, takes place in the upwelling and downwelling regions of the model flow. With the meridional shifts of the MOC during the oscillation, only small regions exist where large APE production coincides with large conversion of APE to kinetic energy. 

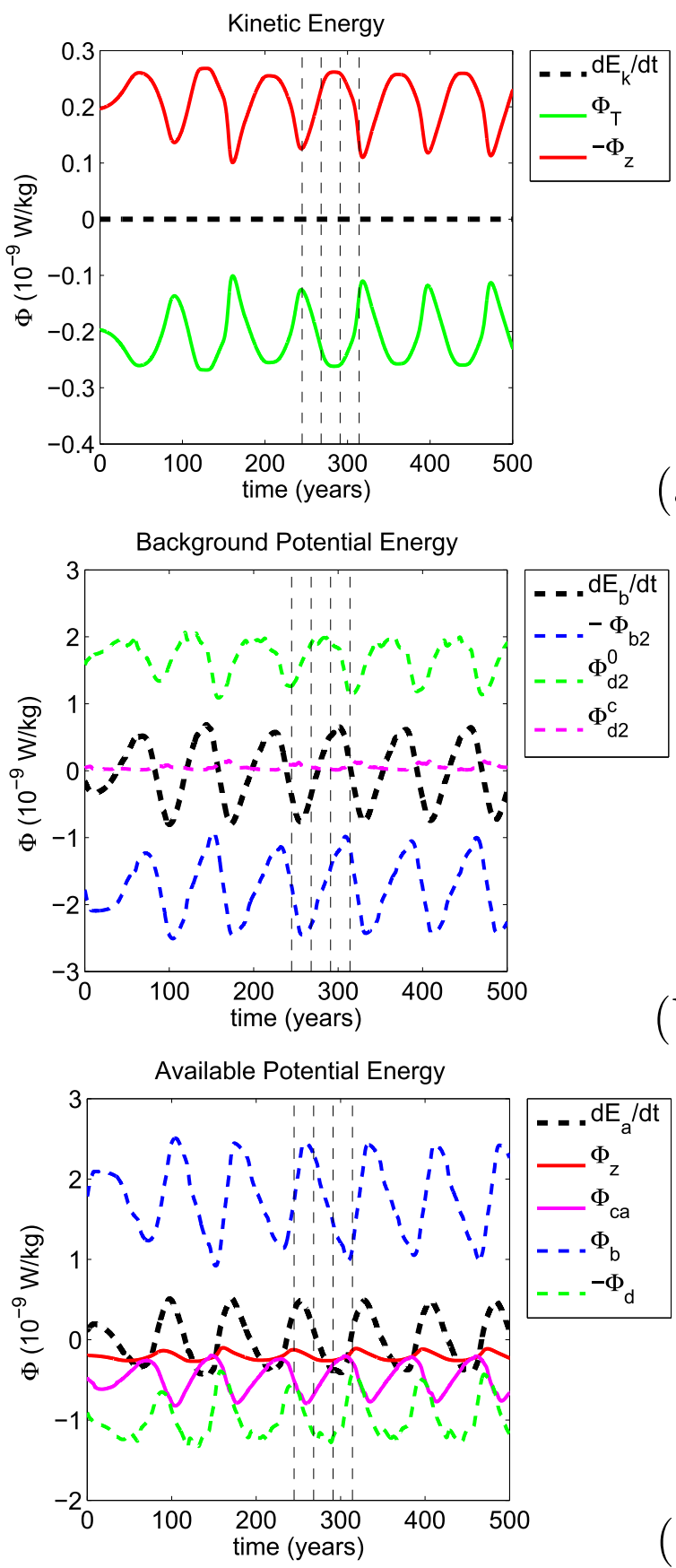

(b)

FIG. 8. (a) Terms in the kinetic energy equation. (b) Terms in the background potential energy equation. (c) Terms in the available potential energy equation.

\section{Summary, discussion, and conclusions}

The subject of horizontal convection is a very interesting problem and a highly relevant one for the ocean. Most papers have focused on how to understand the present-day time-mean ocean circulation from an energetic point of view and in particular the role of surface buoyancy fluxes [see the overviews in Wunsch and Ferrari (2004) and Hughes and Griffiths (2008)]. The main discussion is on whether the surface buoyancy forcing does substantially contribute to the energy needed to maintain the global ocean circulation (Ferrari and Wunsch 2009; Hughes et al. 2009).

In a so-called minimal model (Dijkstra 2013) of the Atlantic multidecadal oscillation used here, a relatively large value of $K_{V}^{0}$ (the background value of the vertical mixing coefficient of heat) is applied. This value is tuned such that the mean MOC strength matches observed values and hence $K_{V}^{0}$ represents the effects of other processes (winds, tides) than buoyancy-induced mixing generating the time-mean MOC.

However, the new element here is that (while fixing $K_{V}^{0}$ ) variability in the MOC arises under a prescribed heat flux, due to a large-scale instability associated with a thermal Rossby mode. In the minimal model, one can compute closed (up to discretization error) energy balances and the effect of convective adjustment is explicitly computed. There is, of course, a caveat on the energetics of this process as there is no direct coupling of potential energy changes due to convection and kinetic energy (Hughes et al. 2009), but only an indirect one through the available potential energy balance. However, in the hydrostatic Boussinesq model, as used here, there is no other way to incorporate these effects.

The central quantity related to the strength of the MOC is the term $\Phi_{z}$, which represents the conversion of available potential energy to kinetic energy. This term arises as a residual in the available potential energy balance equation that is controlled by phase differences between available potential energy sources (through the surface buoyancy flux) and sinks (irreversible mixing, convective adjustment) introduced by the propagation of the temperature anomalies.

Sea surface temperature perturbations associated with the thermal Rossby mode move westward in this model, strengthening and weakening the MOC and leading to changes in the basinwide density field. The propagation of the temperature anomaly hence also leads to temporal and spatial changes in the state of minimal potential energy (or background state) and hence to changes in available potential energy. The strength of the MOC controls the sinking region and hence the meridional extent of the gradients in the background field $z_{*}$, which affect the production of available potential energy $\Phi_{b 2}$. The energetic description of the multidecadal variability can therefore be directly coupled to the term $\Phi_{b 2}$. When $\Phi_{b 2}$ is large, the residual term $\Phi_{z}$ is strongly negative, as only part of the production is used to raise the available potential energy in the system, and the MOC strength increases. This causes the sinking 


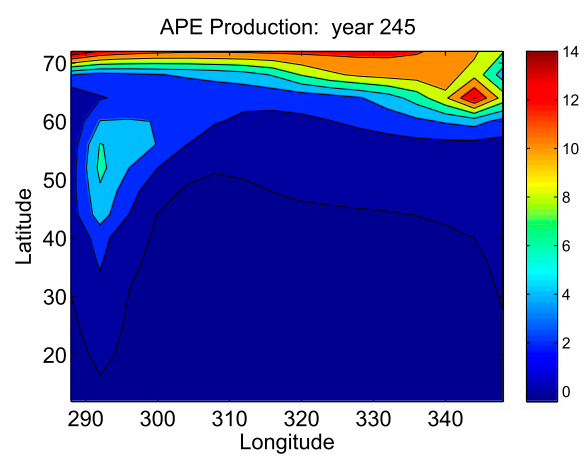

(a)
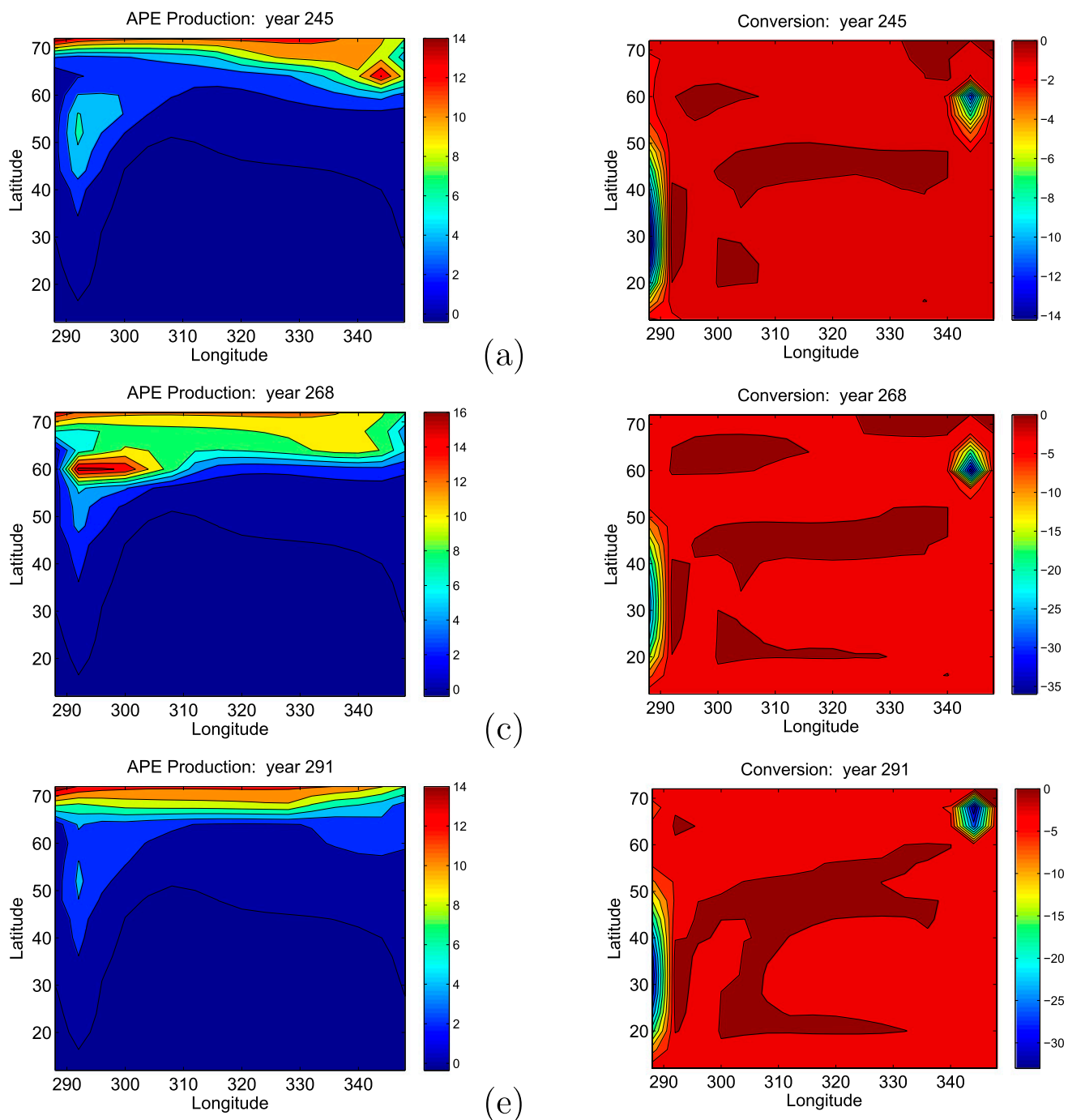

(c)

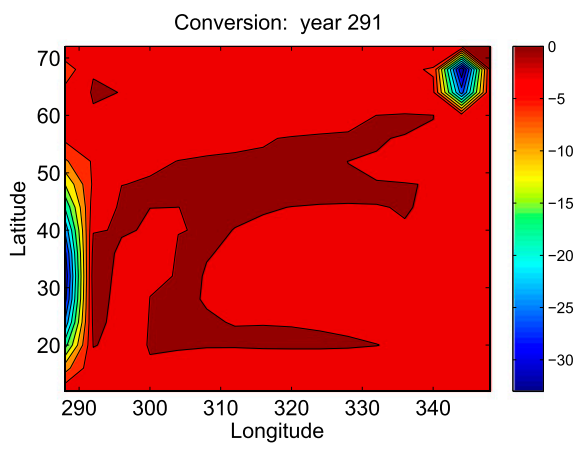

(e)
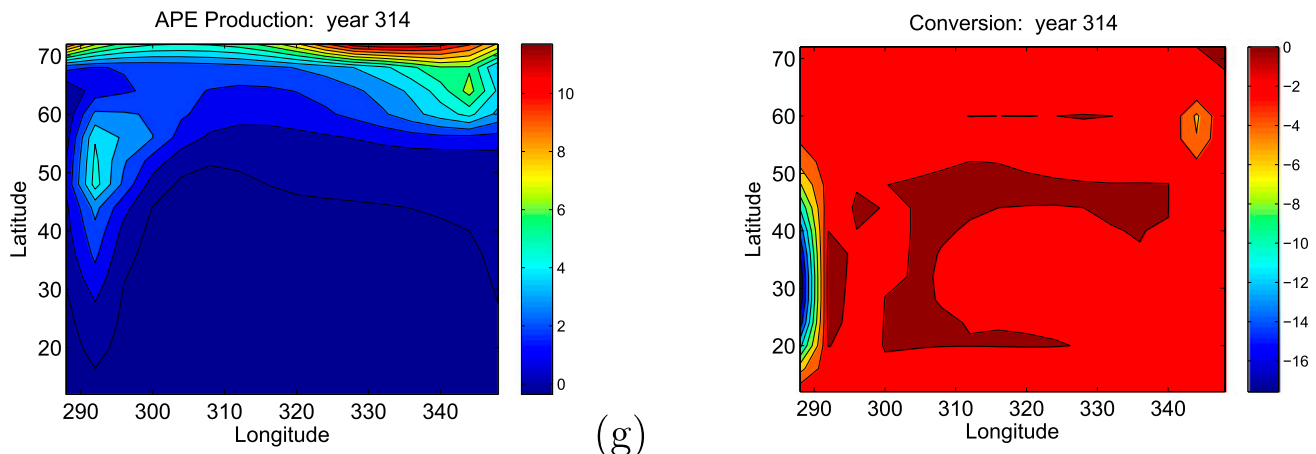

FIG. 9. (left) APE production term $z_{*}(\phi, \theta, 0) Q_{S}(\phi, \theta)$ (in units of $\left.10^{4} \mathrm{~W} \mathrm{~m}^{-1}\right)$ and (right) APE-kinetic energy conversion term $\int_{-H}^{0}-\mathbf{u}_{h} \cdot \nabla_{h} p d z$ (in units of $10^{6} \mathrm{~W} \mathrm{~m}^{-2}$ ) at four different times during the evolution of the flow: (a),(b) 245, (c),(d) 268, (e),(f) 291, and (g),(h) $314 \mathrm{yr}$.

regions to move northward and hence the production term $\Phi_{b 2}$ decreases.

Together with the series of studies linking the results of the minimal model to the Atlantic multidecadal oscillation (Frankcombe et al. 2010), we may have obtained a first view on the energetics of this phenomenon. Even when wind forcing and freshwater fluxes are included in the minimal model, the variability is mainly 
caused by the thermal Rossby mode mechanism (Te Raa and Dijkstra 2003). In the presence of steady background mixing, the energy source for the variability originates from surface buoyancy fluxes, which is converted (from available potential energy) to kinetic energy. Thus, even if the mean MOC were dominantly driven by the wind and tides, we argue that the multidecadal variability on this mean state is buoyancy driven.

Acknowledgments. HD thanks the hospitality of the Research School of Earth Sciences at the Australian National University, during a most enjoyable visit in Canberra from September 2011 to January 2012. This visit was partially funded through the ARC Centre of Excellence for Climate System Science (CE11E0098). $\mathrm{AMH}$ is supported by ARC Future Fellowship FT120100842, and JAS is supported by the ARC Discovery Projects DP0986244 and DP120102744. HD also thanks Johan Nilsson, Jonas Nycander, and Fabian Roquet (Meteorological Institute, University of Stockholm, Sweden) for most useful discussions. We also thank Rémi Tailleux and another anonymous reviewer for the useful comments that substantially improved the paper.

\section{APPENDIX}

\section{Model Formulation}

With $r_{0}$ and $\Omega$ being the radius and angular velocity of Earth, the governing equations for the zonal, meridional, and vertical velocity $u, v$, and $w$ and the dynamic pressure $p$ (the hydrostatic part has been subtracted) become

$$
\begin{gathered}
\frac{D u}{d t}-u v \tan \theta-2 \Omega v \sin \theta+\frac{1}{\rho_{0} r_{0} \cos \theta} \frac{\partial p}{\partial \phi} \\
=A_{V} \frac{\partial^{2} u}{\partial z^{2}}+A_{H} L_{u}(u, v)+\frac{\tau^{\phi}}{\rho_{0} H_{m}} \mathcal{G}(z) \\
\frac{D v}{d t}+u^{2} \tan \theta+2 \Omega u \sin \theta+\frac{1}{\rho_{0} r_{0}} \frac{\partial p}{\partial \theta} \\
=A_{V} \frac{\partial^{2} v}{\partial z^{2}}+A_{H} L_{v}(u, v)+\frac{\tau^{\theta}}{\rho_{0} H_{m}} \mathcal{G}(z) \\
\frac{\partial p}{\partial z}=g \rho_{0} \alpha_{T} T, \\
\frac{\partial w}{\partial z}+\frac{1}{r_{0} \cos \theta}\left[\frac{\partial u}{\partial \phi}+\frac{\partial(v \cos \theta)}{\partial \theta}\right]=0,
\end{gathered}
$$

$$
\frac{D T}{d t}-K_{H} \nabla_{H}^{2} T-\frac{\partial}{\partial z}\left(K_{V} \frac{\partial T}{\partial z}\right)=\frac{Q_{S}}{\rho_{0} C_{p} H_{m}} \mathcal{G}(z),
$$

where $\mathcal{G}(z)=\mathcal{H}\left(z / H_{m}+1\right), \mathcal{H}$ is a continuous approximation of the Heaviside function, and $C_{p}$ is a constant heat capacity. In addition,

$$
\begin{aligned}
\frac{D}{d t} & =\frac{\partial}{\partial t}+\frac{u}{r_{0} \cos \theta} \frac{\partial}{\partial \phi}+\frac{v}{r_{0}} \frac{\partial}{\partial \theta}+w \frac{\partial}{\partial z} \\
L_{u}(u, v) & =\nabla_{H}^{2} u+\frac{u \cos 2 \theta}{r_{0}^{2} \cos ^{2} \theta}-\frac{2 \sin \theta}{r_{0}^{2} \cos ^{2} \theta} \frac{\partial v}{\partial \phi} \\
L_{v}(u, v) & =\nabla_{H}^{2} v+\frac{v \cos 2 \theta}{r_{0}^{2} \cos ^{2} \theta}+\frac{2 \sin \theta}{r_{0}^{2} \cos ^{2} \theta} \frac{\partial u}{\partial \phi} \\
\nabla_{H}^{2} & =\frac{1}{r_{0}^{2} \cos \theta}\left[\frac{\partial}{\partial \phi}\left(\frac{1}{\cos \theta} \frac{\partial}{\partial \phi}\right)+\frac{\partial}{\partial \theta}\left(\cos \theta \frac{\partial}{\partial \theta}\right)\right]
\end{aligned}
$$

In Eqs. (A1a) and (A1b), $A_{H}$ and $A_{V}$ are the horizontal and vertical momentum (eddy) viscosity, which we will take as constant.

Slip conditions are assumed at the bottom boundary, while at all lateral boundaries no-slip conditions are applied. At all lateral boundaries and the bottom boundary, the heat flux is zero. Since the forcing is represented as a body force over the first layer, slip and no-flux conditions apply at the ocean surface. Hence, the boundary conditions are

$$
\begin{aligned}
& z=-H, 0: \frac{\partial u}{\partial z}=\frac{\partial v}{\partial z}=w=\frac{\partial T}{\partial z}=0, \\
& \phi=\phi_{w}, \phi_{e}: u=v=w=\frac{\partial T}{\partial \phi}=0, \\
& \theta=\theta_{s}, \theta_{n}: u=v=w=\frac{\partial T}{\partial \theta}=0 .
\end{aligned}
$$

Parameters that are fixed in the calculations described in section 4 are the same as in typical large-scale lowresolution ocean general circulation models and their values are listed in Table 1.

In the case of an unstable stratification, additional mixing occurs through convective overturning. We can take this mixing into account through an additional mixing coefficient $K_{V}^{c} \gg K_{V}^{0}$ by formulating $K_{V}$ as

$$
K_{V}=K_{V}^{0}+\mathcal{F}\left(N_{b}^{2}\right) K_{V}^{c} ; \quad N_{b}^{2}=-\frac{g}{\rho_{0}} \frac{\partial \rho}{\partial z} .
$$

Here $\mathcal{F}$ is a mixing profile function, which we take as

$$
\mathcal{F}(x)=\max \left\{\tanh \left(-x^{3}\right), 0\right\},
$$

such that additional convective mixing is generated smoothly as soon as $N_{b}^{2}<0$. 


\section{REFERENCES}

Atkinson, K. E., 1989: An Introduction to Numerical Analysis. John Wiley and Sons, $712 \mathrm{pp}$.

Chylek, P., C. K. Folland, H. A. Dijkstra, G. Lesins, and M. K. Dubey, 2011: Ice-core data evidence for a prominent near 20 year time-scale of the Atlantic Multidecadal Oscillation. Geophys. Res. Lett., 38, L13704, doi:10.1029/2011GL047501.

- _ , L. Frankcombe, H. Dijkstra, G. Lesins, and M. Dubey, 2012: Greenland ice core evidence for spatial and temporal variability of the Atlantic multidecadal oscillation. Geophys. Res. Lett., 39, L09705, doi:10.1029/2012GL051241.

Delworth, T. L., and R. G. Greatbatch, 2000: Multidecadal thermohaline circulation variability driven by atmospheric surface flux forcing. J. Climate, 13, 1481-1495, doi:10.1175/ 1520-0442(2000)013<1481:MTCVDB > 2.0.CO;2.

— S. Manabe, and R. J. Stouffer, 1993: Interdecadal variations of the thermohaline circulation in a coupled ocean-atmosphere model. J. Climate, 6, 1993-2011, doi:10.1175/1520-0442(1993)006<1993: IVOTTC $>2.0 . \mathrm{CO} ; 2$.

de Niet, A. C., F. Wubs, A. D. Terwisscha van Scheltinga, and H. A. Dijkstra, 2007: A tailored solver for bifurcation analysis of oceanclimate models. J. Comput. Phys., 227, 654-679, doi:10.1016/ j.jcp.2007.08.006; Corrigendum, 228, 4962-4964, doi:10.1016/ j.jcp.2009.04.002.

Den Toom, M., and H. A. Dijkstra, 2011: Scaling of the strength of the meridional overturning with vertical diffusivity in an idealized global ocean geometry. Tellus, 63A, 354-370, doi:10.1111/ j.1600-0870.2010.00496.x.

Dijkstra, H. A., 2005: Nonlinear Physical Oceanography: A Dynamical Systems Approach to the Large-Scale Ocean Circulation and El Niño. 2nd ed. Springer, 532 pp.

— 2013: Nonlinear Climate Dynamics. Cambridge University Press, $370 \mathrm{pp}$.

Dima, M., and G. Lohmann, 2007: A hemispheric mechanism for the Atlantic multidecadal oscillation. J. Climate, 20, 27062719, doi:10.1175/JCLI4174.1.

Dong, B., and R. Sutton, 2005: Mechanism of interdecadal thermohaline circulation variability in a coupled ocean-atmosphere GCM. J. Climate, 18, 1117-1135, doi:10.1175/JCLI3328.1.

Eden, C., and T. Jung, 2001: North Atlantic interdecadal variability: Oceanic response to the North Atlantic Oscillation (1865-1997). J. Climate, 14, 676-691, doi:10.1175/1520-0442(2001)014<0676: NAIVOR $>2.0 . \mathrm{CO} ; 2$.

Enfield, D. B., A. M. Mestas-Nuñes, and P. Trimble, 2001: The Atlantic multidecadal oscillation and its relation to rainfall and river flows in the continental U.S. Geophys. Res. Lett., 28, 2077-2080, doi:10.1029/2000GL012745.

Ferrari, R., and C. Wunsch, 2009: Ocean circulation kinetic energy: Reservoirs, sources, and sinks. Annu. Rev. Fluid Mech., 41, 253-282, doi:10.1146/annurev.fluid.40.111406.102139.

Frankcombe, L. M., and H. A. Dijkstra, 2009: Coherent multidecadal variability in North Atlantic sea level. Geophys. Res. Lett., 36, L15604, doi:10.1029/2009GL039455.

— North Atlantic multidecadal climate variability. Geophys. Res. Lett., 38, L16603, doi:10.1029/2011GL048158.

,-- , and A. von der Heydt, 2008: Sub-surface signatures of the Atlantic multidecadal oscillation. Geophys. Res. Lett., 35, L19602, doi:10.1029/2008GL034989.

- ——, and — 2009: Noise-induced multidecadal variability in the North Atlantic: Excitation of normal modes. J. Phys. Oceanogr., 39, 220-233, doi:10.1175/2008JPO3951.1.
- A. von der Heydt, and H. A. Dijkstra, 2010: North Atlantic multidecadal climate variability: An investigation of dominant time scales and processes. J. Climate, 23, 3626-3638, doi:10.1175/ 2010JCLI3471.1.

Gregory, J. M., and R. Tailleux, 2011: Kinetic energy analysis of the response of the Atlantic meridional overturning circulation to $\mathrm{CO}_{2}$-forced climate change. Climate Dyn., 37, 893914, doi:10.1007/s00382-010-0847-6.

Hogg, A. M., H. A. Dijkstra, and J. A. Saenz, 2013: The energetics of a collapsing meridional overturning circulation. J. Phys. Oceanogr., 43, 1512-1524, doi:10.1175/ JPO-D-12-0212.1.

Huang, R., 1998: Mixing and available potential energy in a Boussinesq ocean. J. Phys. Oceanogr., 28, 669-678, doi:10.1175/ 1520-0485(1998)028<0669:MAAPEI > 2.0.CO;2.

Huck, T., A. Colin de Verdière, and A. J. Weaver, 1999: Interdecadal variability of the thermohaline circulation in box-ocean models forced by fixed surface fluxes. J. Phys. Oceanogr., 29, 865-892, doi:10.1175/1520-0485(1999)029<0865: IVOTTC $>2.0 . \mathrm{CO} ; 2$.

Hughes, G. O., and R. W. Griffiths, 2008: Horizontal convection. Annu. Rev. Fluid Mech., 40, 185-208, doi:10.1146/ annurev.fluid.40.111406.102148.

_ energy and irreversible mixing in the meridional overturning circulation. J. Phys. Oceanogr., 39, 3130-3146, doi:10.1175/ 2009JPO4162.1.

Jungclaus, J. H., H. Haak, M. Latif, and U. Mikolajewicz, 2005: Arctic-North Atlantic interactions and multidecadal variability of the meridional overturning circulation. J. Climate, 18, 4013-4031, doi:10.1175/JCLI3462.1.

_, N. Keenlyside, M. Botzet, H. Haak, J.-J. Luo, J. Marotzke, U. Mikolajewicz, and E. Roeckner, 2006: Ocean circulation and tropical variability in the coupled model ECHAM5/MPI-OM. J. Climate, 19, 3952-3972, doi:10.1175/ JCLI3827.1.

Keller, H. B., 1977: Numerical solution of bifurcation and nonlinear eigenvalue problems. Applications of Bifurcation Theory, P. H. Rabinowitz, Ed., Academic Press, 359385.

Knight, J. R., R. J. Allan, C. K. Folland, M. Vellinga, and M. E. Mann, 2005: A signature of persistent natural thermohaline circulation cycles in observed climate. Geophys. Res. Lett., 32, L20708, doi:10.1029/2005GL024233.

Kuhlbrodt, T., A. Griesel, M. Montoya, A. Levermann, M. Hofmann, and S. Rahmstorf, 2007: On the driving processes of the Atlantic meridional overturning circulation. Rev. Geophys., 45, RG2001, doi:10.1029/2004RG000166.

Kushnir, Y., 1994: Interdecadal variations in North Atlantic sea surface temperature and associated atmospheric conditions. J. Phys. Oceanogr., 7, 141-157.

Lee, S.-K., and C. Wang, 2010: Delayed advective oscillation of the Atlantic thermohaline circulation. J. Climate, 23, 1254-1261, doi:10.1175/2009JCLI3339.1.

Lorenz, E. N., 1955: Available potential energy and the maintenance of the general circulation. Tellus, 7, 157-167, doi:10.1111/ j.2153-3490.1955.tb01148.x.

Polyakov, I. V., and Coauthors, 2003: Long term ice variability in Arctic marginal seas. J. Climate, 16, 2078-2085, doi:10.1175/ 1520-0442(2003)016<2078:LIVIAM >2.0.CO;2.

- and Coauthors, 2004: Variability of the Intermediate Atlantic Water of the Arctic Ocean over the last 100 years. J. Climate, 17, 4485-4497, doi:10.1175/JCLI-3224.1. 
Roquet, F., 2013: Dynamical potential energy: A new approach to ocean energetics. J. Phys. Oceanogr., 43, 457-476, doi:10.1175/ JPO-D-12-098.1.

Saenz, J. A., A. McC. Hogg, G. O. Hughes, and R. W. Griffiths, 2012: Mechanical power input from buoyancy and wind to the circulation in an ocean model. Geophys. Res. Lett., 39, L13605, doi:10.1029/2012GL052035.

Schlesinger, M. E., and N. Ramankutty, 1994: An oscillation in the global climate system of period $65-70$ years. Nature, 367, 723 726, doi:10.1038/367723a0.

Scotti, A., and B. White, 2011: Is horizontal convection really "nonturbulent?" Geophys. Res. Lett., 38, L21609, doi:10.1029/ 2011 GL049701.

Sevellec, F., and A. V. Fedorov, 2013: The leading, interdecadal eigenmode of the Atlantic Meridional overturning circulation in a realistic ocean model. J. Climate, 26, 2160-2183, doi:10.1175/JCLI-D-11-00023.1.

Tailleux, R., 2009: On the energetics of stratified turbulent mixing, irreversible thermodynamics, Boussinesq models and the ocean heat engine controversy. J. Fluid Mech., 638, 339-382, doi:10.1017/S002211200999111X.

_ 2013: Available potential energy and energy in stratified fluids. Annu. Rev. Fluid Mech., 45, 35-58, doi:10.1146/ annurev-fluid-011212-140620.

Te Raa, L. A., and H. A. Dijkstra, 2002: Instability of the thermohaline ocean circulation on interdecadal time scales. J. Phys. Oceanogr., 32,138-160, doi:10.1175/1520-0485(2002)032<0138: IOTTOC $>2.0 . \mathrm{CO} ; 2$
— and - 2003: Modes of internal thermohaline variability in a single-hemispheric ocean basin. J. Mar. Res., 61, 491-516, doi:10.1357/002224003322384906.

Timmermann, A., M. Latif, R. Voss, and A. Grötzner, 1998: Northern Hemisphere interdecadal variability: A coupled air-sea mode. J. Climate, 11, 1906-1931, doi:10.1175/ 1520-0442-11.8.1906.

Vellinga, M., and P. Wu, 2004: Low-latitude freshwater influence on centennial variability of the Atlantic thermohaline circulation. J. Climate, 17, 4498-4511, doi:10.1175/3219.1.

Venegas, S., and L. Mysak, 2000: Is there a dominant timescale of natural climate variability in the Arctic? J. Climate, 13, 3412-3434, doi:10.1175/1520-0442(2000)013<3412: ITADTO $>2.0 . \mathrm{CO} ; 2$.

Vincze, M., I. M. Jánosi, E. Barsy, T. Tél, and A. Várai, 2012: An experimental study of the Atlantic variability on interdecadal timescales. Nonlinear Processes Geophys., 19, 335-343, doi:10.5194/ npg-19-335-2012.

Winters, K., P. N. Lombard, J. J. Riley, and E. A. D'Asaro, 1995: Available potential energy and mixing in densitystratified fluids. J. Fluid Mech., 289, 115-128, doi:10.1017/ S002211209500125X.

Wunsch, C., and R. Ferrari, 2004: Vertical mixing, energy and the general circulation of the oceans. Annu. Rev. Fluid Mech., 36, 281-314, doi:10.1146/annurev.fluid.36.050802.122121.

Zhang, R., 2008: Coherent surface-subsurface fingerprint of the Atlantic meridional overturning circulation. Geophys. Res. Lett., 35, L20705, doi:10.1029/2008GL035463. 